\title{
Effects of Parathyroid Hormone on Skeletal Muscle Protein and Amino Acid Metabolism in the Rat
}

\author{
Alan J. Garber, Departments of Medicine, Biochemistry and Cell Biology, \\ Baylor College of Medicine, The Methodist Hospital, Houston, Texas 77030
}

A B S T R A C T Because prominent skeletal muscle dysfunction and muscle wasting are seen in both chronic uremia and in primary hyperparathyroidism, and because markedly elevated parathyroid hormone levels occur in both disorders, potential effects of parathyroid hormone on skeletal muscle protein, amino acid, and cyclic nucleotide metabolism were studied in vitro using isolated intact rat epitrochlearis skeletal muscle preparations. Intact bovine parathyroid hormone and the synthetic 1-34 fragment of this hormone stimulated the release of alanine and glutamine from muscle of control but not from chronically uremic animals. This stimulation was dependent upon the concentration of parathyroid hormone added: At $10^{5} \mathrm{ng} / \mathrm{ml}$ parathyroid hormone increased alanine release $84 \%$ and glutamine release $75 \%$. Intracellular levels of alanine and glutamine were not altered by parathyroid hormone. Increasing concentrations of the 1-34 polypeptide decreased $\left[{ }^{3} \mathrm{H}\right]$ leucine incorporation into protein of muscles from both control and uremic animals. Using muscles from animals given a pulse-chase label of [guanido- ${ }^{14} \mathrm{C}$ ]arginine in vivo, parathyroid hormone increased the rate of loss of ${ }^{14} \mathrm{C}$ label from acid-precipitable protein during incubation and correspondingly increased the rate of appearance of this label in the incubation media. Parathyroid hormone increased muscle cAMP levels by $140 \%$ and cGMP levels by $185 \%$, but had no effect on skeletal muscle cyclic nucleotide phosphodiesterase activities as assayed in vitro. Adenylyl cyclase activity in membrane preparations from control but not uremic rats was stimulated by parathyroid hormone in a concentration-dependent fashion. However, no stimulation of guanylyl cyclase activity was noted by parathyroid hormone, although stimulation by sodium azide was present. Incubation of muscles with added parathyroid hormone produced a diminished responsiveness towards epinephrine or

Received for publication 1 November 1982 and in revised form 25 January 1983. serotonin regulation of amino acid release and cAMP formation in the presence compared to the absence of parathyroid hormone. In the absence of parathyroid hormone, detectable inhibition of alanine and glutamine release was produced by $10^{-9} \mathrm{M}$ epinephrine, whereas in the presence of parathyroid hormone $(1,000 \mathrm{ng} / \mathrm{ml})$ inhibition of alanine and glutamine release required $10^{-6} \mathrm{M}$ or greater epinephrine. Resistance to cyclic AMP action as well as inhibition of cyclic AMP formation by parathyroid hormone was found. Preincubation of rat sarcolemma with 1-34 parathyroid hormone produced a decreased activity of the isoproterenol-stimulable adenylyl cyclase activity but there was no apparent change in the concentration of isoproterenol required for one-half maximal and maximal stimulation of the enzyme.

These findings suggest that high levels of parathyroid hormone have direct effects on skeletal muscle protein, amino acid, and cyclic nucleotide metabolism in muscle of normal but not uremic animals. Treatment with these high levels of parathyroid hormone in vitro appears to reproduce in normal muscle, the metabolic deficits and loss of hormone responsiveness observed in muscle of chronically uremic animals. It is therefore possible that direct effects of parathyroid hormone on skeletal muscle may account in part for the muscle dysfunction and wasting of primary hyperparathyroidism and chronic uremia.

\section{INTRODUCTION}

Chronic renal failure is accompanied by skeletal muscle dysfunction, muscle wasting, and a spectrum of disorders of carbohydrate metabolism ranging from carbohydrate intolerance and even fasting hyperglycemia to the occasional occurrence of spontaneous hypoglycemia (1-5). Markedly elevated levels of parathyroid hormone and profound secondary hyperparathyroidism are early concomitants of advancing renal insufficiency (6). Primary hyperparathyroidism is also associated with a diffuse neuromuscular defect and 
prominent muscle dysfunction (7-9). Skeletal muscle preparations from rats made chronically uremic by surgery release large quantities of alanine and glutamine in vitro. This appears to result, in part, from an increased rate of protein degradation in muscles from uremic animals $(10,11)$. Since both chronic renal insufficiency and hyperparathyroidism are associated with substantial elevations in the circulating levels of parathyroid hormone, and since both disease states have a significant muscle dysfunction and wasting disorder associated with them, a relationship between the elevated levels of parathyroid hormone and the disordered skeletal muscle metabolism of both disease complexes seems possible. For these reasons, we have investigated the effects of parathyroid hormone and its synthetic 1-34 fragment on protein, amino acid, and cyclic nucleotide metabolism in skeletal muscle preparations of the rat. The potential contributions of these effects of parathyroid hormone to the disordered metabolism found in muscle of chronically uremic rats are discussed.

\section{METHODS}

Alanine aminotransferase (EC 2.6.1.2), glutamate dehydrogenase (EC 1.4.1.3), glutaminase (EC 3.5.1.2), lactate dehydrogenase (EC 1.1.1.27), carbamylcholine, epinephrine $(\mathrm{HCl})$, and other biochemical reagents were obtained from Sigma Chemical Co. (St. Louis, MO). [ $\left.\alpha-{ }^{32} \mathrm{P}\right] \mathrm{GTP}(14.2 \mathrm{Ci} /$ mmol sp act), $\left[{ }^{3} \mathrm{H}\right] \mathrm{cAMP}(21 \mathrm{Ci} / \mathrm{mmol}$ sp act $)$, and $\left[{ }^{3} \mathrm{H}\right] \mathrm{cGMP}$ (16.2 $\mathrm{Ci} / \mathrm{mmol} \mathrm{sp}$ act), were purchased from Amersham Corp. (Arlington Heights, IL); and $\left[\alpha-{ }^{32} \mathrm{P}\right] \mathrm{ATP}(25 \mathrm{Ci} / \mathrm{mmol}$ sp act), from International Nuclear and Chemical Corp. (Irvine, CA). $\left.{ }^{125} I\right] 2$ '- $O$-succinyl cAMP and cGMP tyrosine methyl esters were from Collaborative Research, Inc. (Waltham, MA). The synthetic 1-34 fragment of bovine parathyroid hormone was from Beckman Instruments, Inc. (Palo Alto, CA), and highly purified, intact 1-84 parathyroid hormone was purchased from Wilson Laboratories (Park Forest South, IL). Crystalline glucagon-free insulin was a gift of Dr. J. Galloway (Eli Lilly Co., Indianapolis, IN).

As described previously (10), epitrochlearis preparations were obtained from chronically uremic and control SpragueDawley rats (TIMCO, Houston, TX). Animals were made chronically uremic by unilateral nephrectomy and ligation of two branches of the renal artery of the contralateral kidney. Animals were maintained on a high protein diet and were sacrificed $7 \mathrm{~d}$ after surgery. Intact epitrochlaris muscles were visualized, rapidly removed, rinsed, blotted, and placed in incubation flasks containing $0.5 \mathrm{ml}$ of a modified KrebsHenseleit buffer ( $\mathrm{pH}$ 7.4). Other additions such as amino acids, parathyroid hormone, insulin, and epinephrine were made as indicated. The flasks were gassed with $95 \% \mathrm{O}_{2}-5 \%$ $\mathrm{CO}_{2}$, stoppered, and incubated for $5-60 \mathrm{~min}$ at $37^{\circ} \mathrm{C}$. These preparations remained viable in vitro as judged by phosphocreatine and ATP levels that were not different from levels in vivo. Muscles were then removed from the medium, rinsed, blotted, and frozen in liquid nitrogen. Muscle samples and incubation media were stored at $-80^{\circ} \mathrm{C}$. Frozen muscle preparations were weighed, then homogenized in $1.0 \mathrm{ml}$ icecold $3 \mathrm{M}$ perchloric acid and centrifuged at $4,500 \mathrm{~g}$ for 15 min. The supernatant was neutralized with $3 \mathrm{M}$ potassium hydroxide, $0.4 \mathrm{M}$ imidazole, and $0.7 \mathrm{M}$ potassium chloride, and the potassium perchlorate precipitate was removed by further centrifugation. Semimicro- and microfluorometric enzymatic techniques were used to determine levels of alanine, glutamine, and glutamate in perchlorate extracts of skeletal muscle and in the incubation media as previously described $(12,13)$. In studies measuring the incorporation of amino acids into protein, 17 essential and nonessential amino acids (most at $2.5 \mathrm{mM}$ final concentration) and 1.0 $\mu \mathrm{Ci}\left[4,5-{ }^{3} \mathrm{H}\right]$ leucine were added to the incubation medium. The muscles were incubated for $\mathbf{4 h}$ using continuous gassing by $95 \% \mathrm{O}_{2}-5 \% \mathrm{CO}_{2}$, removed, and frozen as described above. Incorporation of radiolabeled amino acid into skeletal muscle protein was assayed by the appearance of ${ }^{3} \mathrm{H}$ label in the acid-insoluble pellet of the trichloroacetic acid extract of the muscle (10). The frozen incubated muscle was homogenized in $12 \%$ trichloroacetic acid, centrifuged, and the pellet washed twice with $5 \%$ trichloroacetic acid. The acidinsoluble pellet was extracted with ether, air dried, and solubilized with NCS tissue solubilizer (Amersham Corp., Arlington Heights, IL). The latter was counted in a liquid scintillation counter using ACS scintillant (Amersham Corp.).

cAMP and cGMP were determined in trichloroacetic acid extracts of skeletal muscle by double antibody radioimmunoassays using ${ }^{125}$ I-labeled tyrosine methyl esters of succinylated cyclic nucleotides (14). Partial purification of cyclic nucleotides from trichloroacetic acid extracts was obtained by double chromatography over Dowex 50 and aluminum oxide columns (Dow Chemical Co., Midland, MI) as described by Birnbaumer (15) for simultaneous separations of cGMP and cAMP. Tritiated cyclic nucleotides were added to each muscle homogenate to quantitate sample recovery. Although cyclic nucleotide levels were determined after 2 , 5,10 , and $20 \mathrm{~min}$ of incubation with each agonist, only the data for 2 -min incubations with epinephrine, $5 \mathrm{~min}$ with parathyroid hormone, and $10 \mathrm{~min}$ with serotonin are presented because these periods produced the greatest observed increments in cyclic nucleotide levels. Estimations of adenylyl and guanylyl cyclase activities in skeletal muscle homogenates were based on the determination of the rate of production of $\left[{ }^{32} \mathrm{P}\right] \mathrm{cAMP}$ and $\left[{ }^{32} \mathrm{P}\right] \mathrm{cGMP}$ from $\left[\alpha-{ }^{32} \mathrm{P}\right] \mathrm{ATP}$ and $\left[\alpha^{-32} \mathrm{P}\right] \mathrm{GTP}$, respectively, as described (10). The cAMP formed was isolated by a minor modification (16) of the method of Salomon (17). Both isolation methods consist of an initial chromatography over Dowex 50 (AG-X4, 100-200 mesh, $\mathrm{H}^{+}$form) followed by chromatography of the cyclic nucleotide containing eluate from the Dowex 50 column over neutral aluminum oxide. Yields of cyclic nucleotides (as assessed by recovery of tritium-labeled cyclic nucleotides added to each individual sample) were between 60 and $75 \%$ for cAMP and $\mathbf{4 0}$ and $50 \%$ for cGMP. Reaction blanks were between 2 and $4 \mathrm{cpm}$ of added labeled substrate.

For estimations of hormone-stimulable adenylyl or guanylyl cyclase activity hind limb skeletal muscle was removed from 150-g Sprague-Dawley female control or chronically uremic rats, minced, and homogenized by Polytron homogenization (Brinkmann Instruments, Inc., Westbury, NY) using $10 \mathrm{vol}$ of $27 \%$ sucrose containing $10 \mathrm{mM}$ Tris- $\mathrm{HCl}(\mathrm{pH}$ 7.4), $1 \mathrm{mM}$ EDTA, $1.32 \times 10^{-4} \mathrm{M} N$ - $\alpha$-tosyl-l-lysyl chloromethane and $1.42 \times 10^{-5} \mathrm{M}$ tosyl-l-phenylalanyl chloromethane at a setting of $45 \%$ maximum Polytron rheostat setting for $60 \mathrm{~s}$ while being cooled in an ice slurry. The homogenate was filtered through four layers of cheesecloth and centrifuged at $800 \mathrm{~g}$. The supernatant of this fraction was centrifuged at $17,000 \mathrm{~g}$. The resultant pellet contained the membrane-bound adenylyl cyclase. For determination of adenylyl cyclase activities, $17,000-g$ membrane particles 
were incubated in a final vol of $50 \mu$ l containing $25 \mathrm{mM}$ Tris-HCl (pH 7.4), $1 \mathrm{mM}$ EGTA, $1 \mathrm{mM}\left[{ }^{3} \mathrm{H}\right] \mathrm{cAMP}, 2 \mathrm{mM}$ $\mathrm{MgCl}_{2}, 0.1 \mathrm{mM}\left[\alpha{ }^{32} \mathrm{P}\right] \mathrm{ATP}$, and a regenerating system consisting of $0.2 \mathrm{mg} / \mathrm{ml}$ creatine phosphokinase, $20 \mathrm{mM}$ creatine phosphate, $0.02 \mathrm{mg} / \mathrm{ml}$ myokinase, and the indicated agonists. The reaction was started with the addition of $10 \mu \mathrm{l}$ of the membrane preparation $(30-50 \mu \mathrm{g})$, and was continued at $30^{\circ} \mathrm{C}$ for $10 \mathrm{~min}$ and stopped by the addition of $100 \mu \mathrm{l}$ of a solution containing $40 \mathrm{mM}$ ATP, $10 \mathrm{mM}$ cAMP, and $1 \%$ sodium dodecyl sulfate (SDS). Guanylyl cyclase activity was determined in both the supernatant and pellet of a 40,000 $g$ muscle homogenate. Hind limb skeletal muscle was removed from 150-g Sprague-Dawley control and chronically uremic rats, minced, and homogenized in $10 \mathrm{vol}$ of $0.25 \mathrm{M}$ sucrose, $1 \mathrm{mM}$ EDTA, and $10 \mathrm{mM}$ Tris- $\mathrm{HCl}$ (pH 7.4) using a Polytron PT-10 at setting 5.5 for 15-, 25-, then 15-s bursts, with cooling for $30 \mathrm{~s}$ between each burst. The homogenate was centrifuged at $600 \mathrm{~g}$ for $15 \mathrm{~min}$, the pellet discarded, and the supernatant centrifuged for $30 \mathrm{~min}$ at $10,000 \mathrm{~g}$. The supernatant fraction was then centrifuged at $40,000 \mathrm{~g}$ for $45 \mathrm{~min}$. Guanylyl cyclase activity was determined in both the supernatant and pellet of the $40,000 \mathrm{~g}$ fraction. $10 \mu \mathrm{l}$ $(30-50 \mu \mathrm{g})$ of the membrane particles or $20 \mu \mathrm{l}$ of the supernatant were incubated in a total incubation volume containing $25 \mathrm{mM}$ bis-Tris propane (pH 7.5), $1 \mathrm{mM}\left[{ }^{3} \mathrm{H}\right] \mathrm{cGMP}$, $1 \mathrm{mM}$ EDTA, $2.5 \mathrm{mM} \mathrm{MnCl}_{2}, 5 \mathrm{mM}$ dithiothreitol, $0.4 \mathrm{mM}$ $\left[\alpha-{ }^{32} \mathrm{P}\right] \mathrm{GTP}$, the regenerating system, and the agonist indicated. The reaction was started with the addition of membranes and was continued for $10 \mathrm{~min}$ in a $37^{\circ} \mathrm{C}$ water bath and stopped by the addition of $100 \mu \mathrm{l}$ of a solution containing $40 \mathrm{mM}$ GTP, $10 \mathrm{mM}$ cGMP, and 1\% SDS. Protein in the homogenate and membrane preparations was determined using the method of Lowry (18). Statistical assessments of the data were made using Student's $t$ test or analysis of variance as appropriate (19).

\section{RESULTS}

To determine whether or not parathyroid hormone might have direct effects in vitro on skeletal muscle protein and amino acid metabolism, epitrochlearis preparations of rat skeletal muscle were incubated with purified bovine 1-84 parathyroid hormone and with the synthetic 1-34 fragment of bovine parathyroid hormone. As shown in Table $I$, both the native hormone and the 1-34 fragment of parathyroid hormone increased the release of alanine and glutamine from these skeletal muscle preparations. Alanine release was increased $67 \%$ by native parathyroid hormone and $57 \%$ by the 1-34 fragment; glutamine release was increased $60 \%$ by intact parathyroid hormone and $63 \%$ by the $1-34$ fragment $(P<0.01$ for all). Epitrochlearis preparations were also obtained from rats made chronically uremic by unilateral nephrectomy and subtotal ligation of the branches of the contralateral renal artery as described in detail in Methods. These muscle preparations had an increased rate of alanine and glutamine release in the absence of added parathyroid hormone, as has been described previously (10). In contrast to the effect of parathyroid hormone on control muscle preparations, amino acid release from epitrochlaris preparations obtained from uremic rats was not altered by either intact 1-84 parathyroid hormone or the 1-34 fragment. This effect was not the result of the single concentration of parathyroid hormone or the 1-34 fragment studied. As shown in Figs. 1 and 2, added 1-34 parathyroid hormone produced a concentration-dependent increase in the release of both alanine and glutamine from muscle of control rats. At the highest concentration of parathyroid hormone studied $\left(10^{5} \mathrm{ng} / \mathrm{ml}\right)$, alanine release was increased by $84 \%$, and glutamine release was increased by $75 \%(P<0.01$ each $)$. The stimulatory effect of para-

TABLE I

Effect of Bovine Parathyroid Hormone (1-84) and the Synthetic (1-34) Fragment on Amino Acid Release from Skeletal Muscle of Control and Uremic Rats

\begin{tabular}{|c|c|c|c|c|c|}
\hline \multirow[b]{3}{*}{ Addition } & \multirow[b]{3}{*}{ Concentration } & \multicolumn{4}{|c|}{ Release } \\
\hline & & \multicolumn{2}{|c|}{ Alanine } & \multicolumn{2}{|c|}{ Glutamine } \\
\hline & & Control & Uremia & Control & Uremia \\
\hline & $U / m l$ & \multicolumn{4}{|c|}{$\mathrm{nmol} / \mathrm{min} / \mathrm{g}$ muscle } \\
\hline Control & - & $19.8 \pm 2.6$ & $29.7 \pm 1.3$ & $29.4 \pm 2.5$ & $39.9 \pm 2.6$ \\
\hline \multicolumn{6}{|l|}{ Parathyroid hormone } \\
\hline$(1-84)$ & 50 & $33.1 \pm 2.4$ & $29.2 \pm 2.0$ & $46.9 \pm 6.4$ & $40.2 \pm 2.1$ \\
\hline \multicolumn{6}{|l|}{ Synthetic 1-34 } \\
\hline peptide & 57 & $31.1 \pm 3.3$ & $29.5 \pm 1.6$ & $48.0 \pm 5.0$ & $41.0 \pm 3.0$ \\
\hline
\end{tabular}

Epitrochlearis preparations from control and chronically uremic rats were obtained and incubated for $1 \mathrm{~h}$ at $37^{\circ} \mathrm{C}$ in Krebs-Henseleit bicarbonate buffer (pH 7.4) containing glucose $(5 \mathrm{mM})$ and highly purified intact bovine parathyroid hormone or synthetic 1-34 bovine parathyroid hormone at the concentrations indicated. Following conclusion of the 1-h incubation, muscles were rapidly removed from the media, rinsed, blotted, and frozen in liquid nitrogen. Alanine and glutamine released to the media were determined enzymatically using microfluorometric techniques. Values shown are the means $( \pm \mathrm{SEM})$ for at least eight experiments and are expressed as nanomoles of amino acids released per minute per gram muscle, wet weight. 


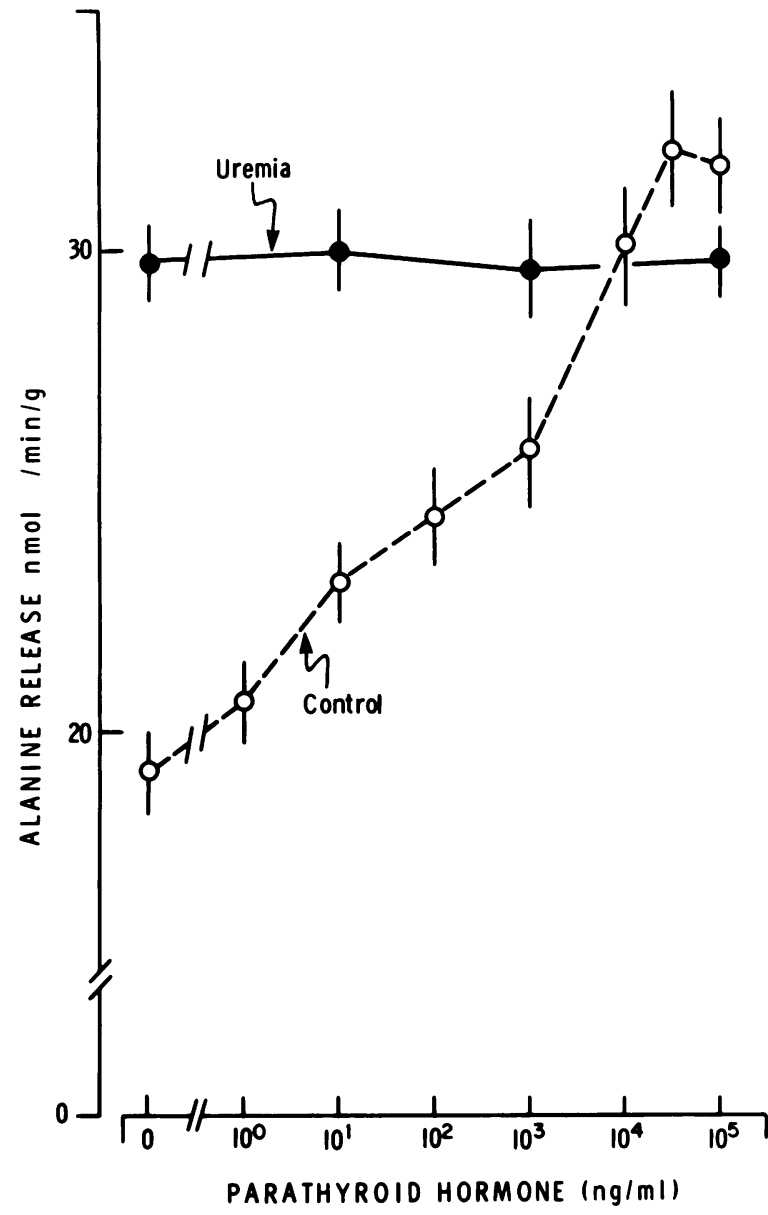

Figure 1 Effect of parathyroid hormone on alanine release from epitrochlearis preparations of rat skeletal muscle. Epitrochlearis preparations were obtained from control $(O)$ and chronically uremic (-) rats and incubated at $37^{\circ} \mathrm{C}$ for $1 \mathrm{~h}$ in Krebs-Henseleit bicarbonate buffer ( $\mathrm{pH}$ 7.4) containing glucose $(5 \mathrm{mM})$ and varying concentrations of synthetic 134 bovine parathyroid hormone as indicated. After incubation, the muscles were rapidly removed, rinsed, blotted, and frozen in liquid nitrogen. Alanine released to the media was determined enzymatically using microfluorometric techniques. Values shown are the means \pm SEM for at least eight experiments and are expressed as nanomoles of alanine released per minute per gram muscle, wet weight.

thyroid hormone on amino acid release appeared to be ultimately saturable at concentrations of parathyroid hormone of $10^{4} \mathrm{ng} / \mathrm{ml}$ or greater. In contrast, the release of alanine and glutamine from muscle of uremic rats was unaltered by parathyroid hormone at any concentration studied, suggesting a complete insensitivity to parathyroid hormone of amino acid release from these muscle preparations.

The metabolic basis for the increased alanine and glutamine release from muscle of normal but not

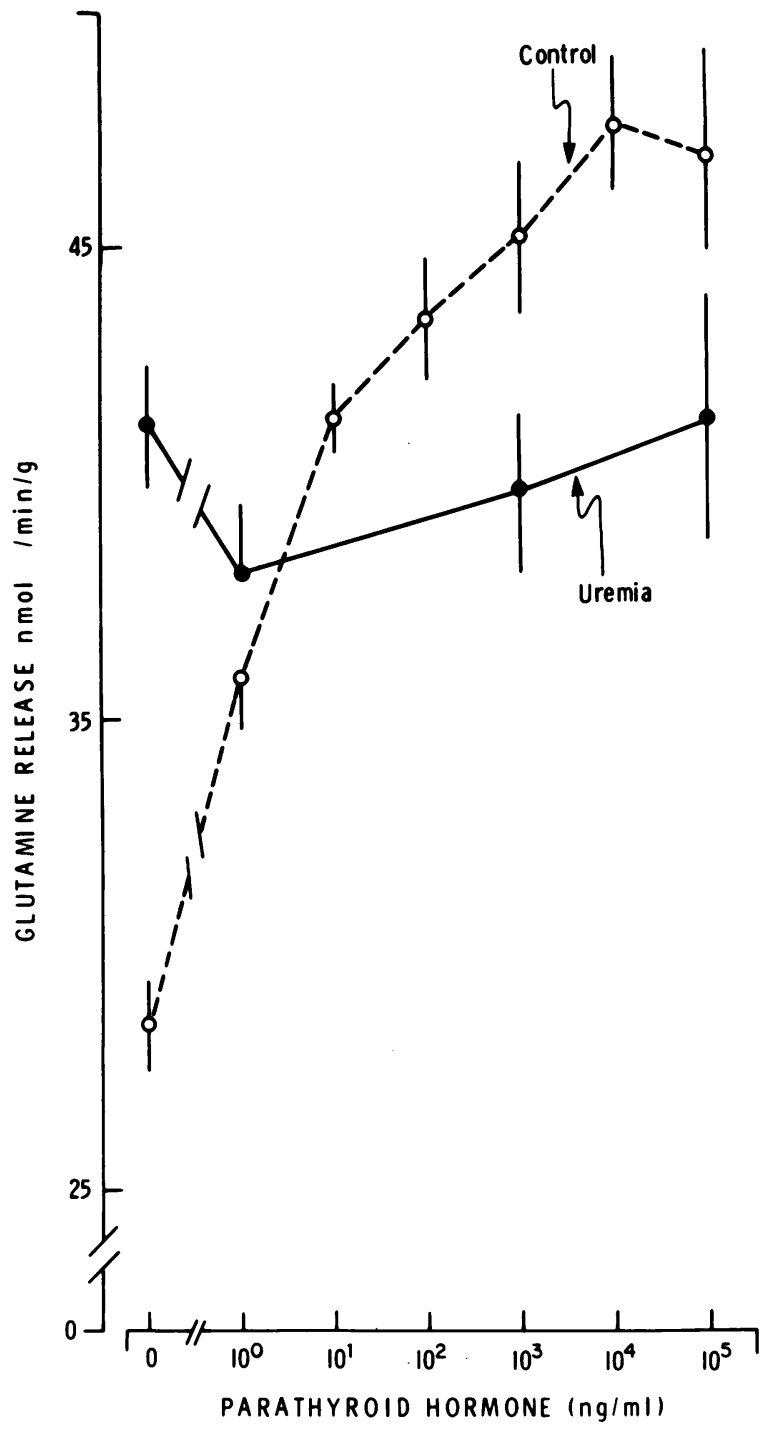

Figure 2 Effect of parathyroid hormone on glutamine release from skeletal muscle. Epitrochlearis preparations were obtained from control $(O)$ and chronically uremic $(\bullet)$ rats and incubated at $37^{\circ} \mathrm{C}$ for $1 \mathrm{~h}$ in Krebs-Henseleit bicarbonate buffer ( $\mathrm{pH} 7.4$ ) containing glucose $(5 \mathrm{mM})$ and varying concentrations of synthetic $1-34$ bovine parathyroid hormone as indicated. After incubation, the muscles were rapidly removed, rinsed, blotted, and frozen in liquid nitrogen. Glutamine released to the media was determined enzymatically using microfluorometric techniques. Values shown are the means $\pm S E M$ for at least eight experiments and are expressed as nanomoles alanine released per minute per gram muscle, wet weight.

uremic rats was next investigated. Since skeletal muscle contains substantial intracellular pools of both alanine and glutamine, it seemed possible that the increased release of amino acids produced by parathy- 
roid hormone might derive from a redistribution of these intracellular pools into the incubation media. However, as shown in Table II, no effect of parathyroid hormone on tissue levels of alanine or glutamine could be observed at any hormone concentration studied. Similarly, no effect on alanine reutilization by way of oxidation to $\mathrm{CO}_{2}$ or reincorporation into protein in these skeletal muscle preparations could be detected (data not shown). Since these findings suggest that an increased net formation of alanine and glutamine was induced by parathyroid hormone addition in vitro, the effect of this hormone on insulin-stimulated protein synthesis was next investigated. As seen in Fig. 3, increasing concentrations of parathyroid hormone caused a decrease in insulin-stimulated $\left[{ }^{3} \mathrm{H}\right]$ leucine incorporation into muscle protein in preparations from control as well as uremic animals. At $10^{5} \mathrm{ng} / \mathrm{ml}$ of parathyroid hormone, leucine incorporation was reduced $\sim 40 \%$ in both control and uremic muscle. In these studies intracellular levels of $\left[{ }^{3} \mathrm{H}\right]$ leucine and leucine specific activities were the same in both normal and uremic muscle, as has been noted previously (10).

Since the foregoing data suggest that parathyroid hormone produces an increased formation and release of alanine and glutamine in muscle from control rats, potential effects of this hormone on protein degradation were qualitatively assessed in vitro using epitrochlearis preparations obtained from rats given a pulsechase label of [guanido- ${ }^{14} \mathrm{C}$ ]arginine as described previously (10). As shown in Table III, incubation in vitro of muscle preparations obtained from rats labeled in

TABLE II

Effect of Synthetic Parathyroid Hormone (1-34) on Amino Acid Tissue Levels in Rat Skeletal Muscle

\begin{tabular}{|c|c|c|}
\hline \multirow{2}{*}{$\begin{array}{l}\text { Parathyroid hormone } \\
\text { concentration }\end{array}$} & \multicolumn{2}{|c|}{ Levels } \\
\hline & Alanine & Glutamine \\
\hline$n g / m l$ & \multicolumn{2}{|c|}{ umol/g muscle } \\
\hline 0 & $1.24 \pm 0.16$ & $3.21 \pm 0.31$ \\
\hline 10 & $1.39 \pm 0.11$ & $2.94 \pm 0.28$ \\
\hline 100 & $1.19 \pm 0.08$ & $3.96 \pm 0.60$ \\
\hline 1000 & $1.20 \pm 0.09$ & $3.03 \pm 0.57$ \\
\hline
\end{tabular}

Epitrochlearis preparations of rat skeletal muscle were obtained and incubated in Krebs-Henseleit bicarbonate buffer for $1 \mathrm{~h}$ at $37^{\circ} \mathrm{C}$. To the incubation media, varying concentrations of $1-34$ synthetic bovine parathyroid hormone were added as indicated. At the conclusion of the incubation, muscles were rapidly removed from the media, rinsed, blotted, and frozen in liquid nitrogen. Alanine and glutamine levels in each muscle preparation were assessed enzymatically using perchloric acid extracts of the muscles. Values shown are the means $( \pm \mathrm{SEM})$ for at least six experiments and expressed as micromoles of amino acid per gram muscle, wet weight.

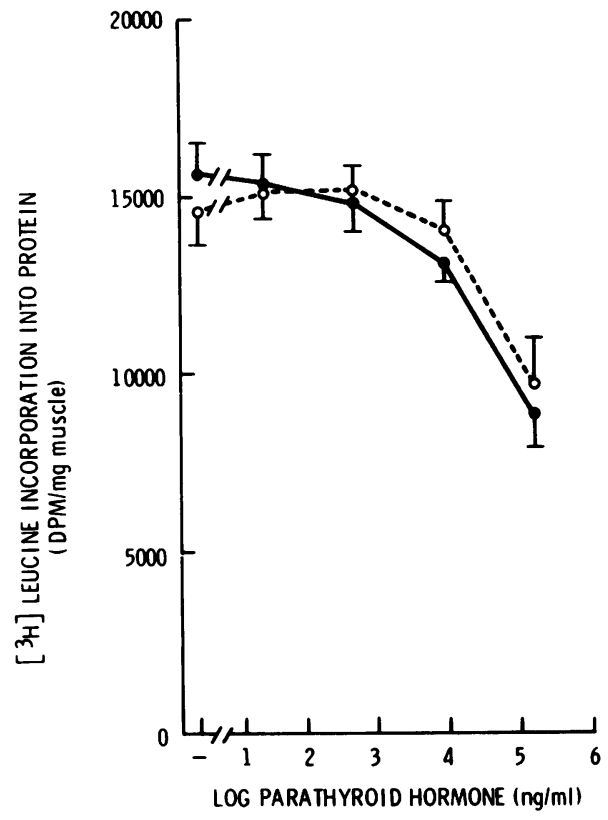

Figure 3 Effect of parathyroid hormone on leucine incorporation into skeletal muscle protein. Epitrochlearis preparations from control $(\bullet)$ and chronically uremic $(O)$ rats were obtained and incubated for $4 \mathrm{~h}$ at $37^{\circ} \mathrm{C}$ under $95 \% \mathrm{O}_{2}-$ $5 \% \mathrm{CO}_{2}$ in Krebs-Henseleit bicarbonate buffer ( $\mathrm{pH} 7.4$ ) containing a mixture of 17 essential and nonessential amino acids, insulin $(100 \mathrm{mU} / \mathrm{ml})$, and glucose $(5 \mathrm{mM})$. To this media, $\left[4,5-{ }^{3} \mathrm{H}\right]$ leucine $(1 \mu \mathrm{Ci} / \mathrm{ml})$ was added. At the conclusion of incubation, the muscles were rapidly removed, rinsed, blotted, and frozen in liquid nitrogen. Incorporation of leucine into trichloroacetic acid-precipitable protein was determined using liquid scintillation spectrometry as described under Methods. Values shown are the means ( \pm SEM) for at least six experiments and are given as disintegrations per minute $\left[{ }^{3} \mathrm{H}\right]$ leucine incorporated/milligram muscle.

vivo resulted in a measurable decline in trichloroacetic acid-insoluble ${ }^{14} \mathrm{C}$-label $(P<0.05)$. Incubation of contralateral epitrochlaris preparations in the presence of synthetic 1-34 parathyroid hormone produced a greater decline in acid insoluble ${ }^{14} \mathrm{C}$-label $(P<0.01)$. The decrements in acid-precipitable label after incubation were matched by appropriate increments in acid-soluble label for both control and parathyroid hormone incubated muscle preparations. Parallel experiments performed in the presence of cycloheximide to inhibit protein resynthesis and hence recycling of label were not different compared to these experiments performed in the absence of cycloheximide (data not shown). Thus, it seems likely that incubation of these muscle preparations in vitro is associated with a measurable rate of loss of labeled amino acid from the acid insoluble to the acid soluble and extracellular pools during incubation. Incubation in the presence of parathyroid hormone accentuated this decline in acid-in- 
TABLE III

Effect of Incubation in the Presence and Absence of Synthetic Parathyroid Hormone on the Distribution of [guanido- ${ }^{14} \mathrm{C}$ ]Arginine in Skeletal Muscle from Rats Previously Labeled In Vivo

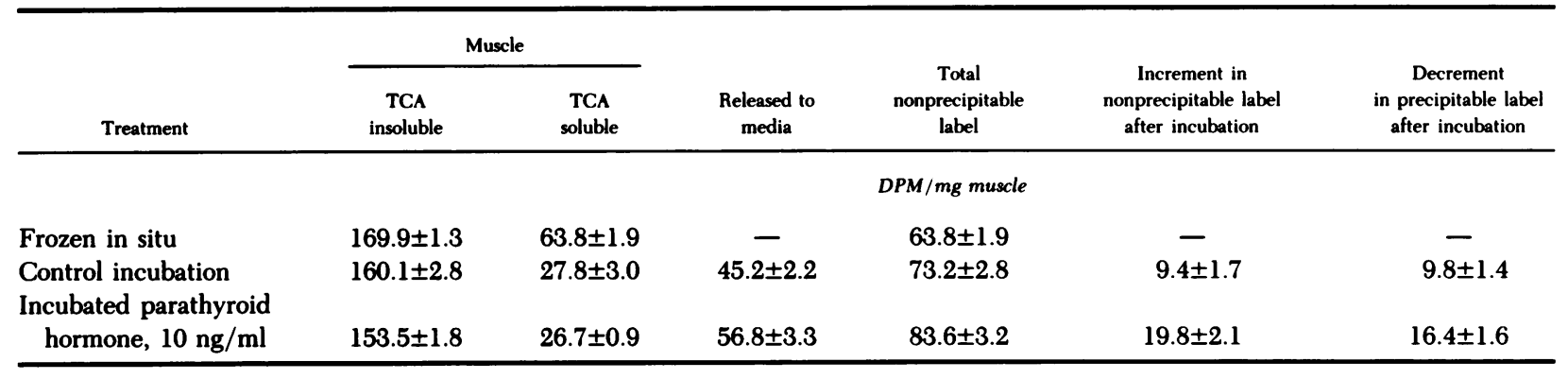

Rats were injected with [guanido- ${ }^{14} \mathrm{C}$ ]arginine as described in Methods. Epitrochlearis preparations from these animals were subsequently obtained and incubated for $2 \mathrm{~h}$ in Krebs-Henseleit bicarbonate buffer ( $\mathrm{pH} 7.4)$ containing glucose $(5 \mathrm{mM})$ in the presence and absence of 1-34 bovine parathyroid hormone. Preparations from the contralateral extremity of each animal were immediately freeze-clamped in situ. After incubation, muscles were removed, rinsed, blotted, and frozen in liquid nitrogen, subsequently homogenized in $12 \%$ trichloroacetic acid and the acid-insoluble pellets washed and subsequently solubilized. Samples of the incubation media, the acid-soluble extract of skeletal muscle, and the acid-insoluble pellet were counted in a liquid scintillation spectrometer. Values shown are the means $( \pm \mathrm{SEM})$ for at least eight experiments and are expressed as disintegrations per minute/gram muscle, wet weight.

soluble label and facilitated the appearance of labeled amino acid in the incubation media and acid-soluble pool of muscle by nearly $100 \%$.

Potential mechanisms by which parathyroid hormone altered protein and amino acid metabolism in skeletal muscle were next investigated. Since the metabolic effects of parathyroid hormone on other tissues such as kidney and bone are thought to be mediated, at least in part, by increased tissue levels of cAMP, the effects of synthetic 1-34 parathyroid hormone on skeletal muscle cAMP and cGMP levels were determined (Figs. 4 and 5). In epitrochlearis preparations obtained from control animals, parathyroid hormone produced a concentration-dependent increase in muscle cAMP levels. At the highest concentrations of hormone studied $(1,000 \mathrm{ng} / \mathrm{ml})$, cAMP levels were increased by $140 \%(P<0.01)$. In contrast, no concentration of parathyroid hormone studied significantly increased cAMP levels in muscles of uremic animals. These same concentrations of parathyroid hormone also produced a concentration-dependent increase in levels of cGMP in muscles obtained from control animals (Fig. 5). The magnitude of the increases in muscle cGMP levels was comparable to the increase in muscle cAMP levels. Levels of cGMP in muscles of uremic animals were slightly higher under basal circumstances in the absence of parathyroid hormone than in muscles of control animals, and parathyroid hormone addition in vitro produced no additional increment in cGMP levels in muscle from uremic as compared to control animals. In order to assess whether these effects of parathyroid hormone on muscle cAMP and cGMP levels resulted from an increased rate of cyclic nucleotide formation or from a diminished rate of cyclic nucleotide disposal,

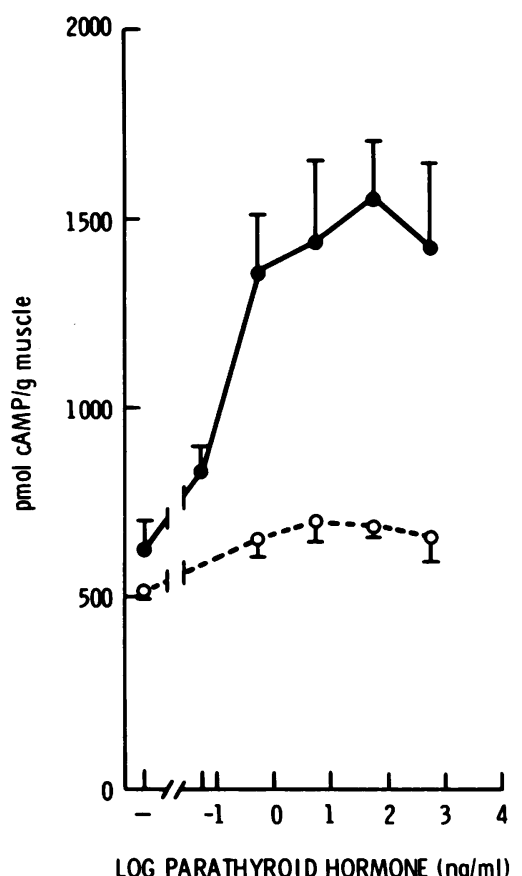

Figure 4 Effect of parathyroid hormone on cAMP levels in skeletal muscle of control and uremic rats. Epitrochlearis preparations from control $(O)$ and chronically uremic (O) rats were obtained and incubated with varying concentrations of parathyroid hormone in Krebs-Henseleit bicarbonate buffer ( $\mathrm{pH} 7.4)$ containing glucose $(5 \mathrm{mM})$. After the conclusion of the incubation, each muscle was rapidly removed, rinsed, blotted, and frozen in liquid nitrogen. Levels of cAMP in trichloroacetic extracts of each skeletal muscle preparation were then determined by double antibody radioimmunoassay. Values shown are the means $( \pm \mathrm{SEM})$ for at least 10 experiments and are given as picomoles of cAMP per gram muscle, wet weight. 


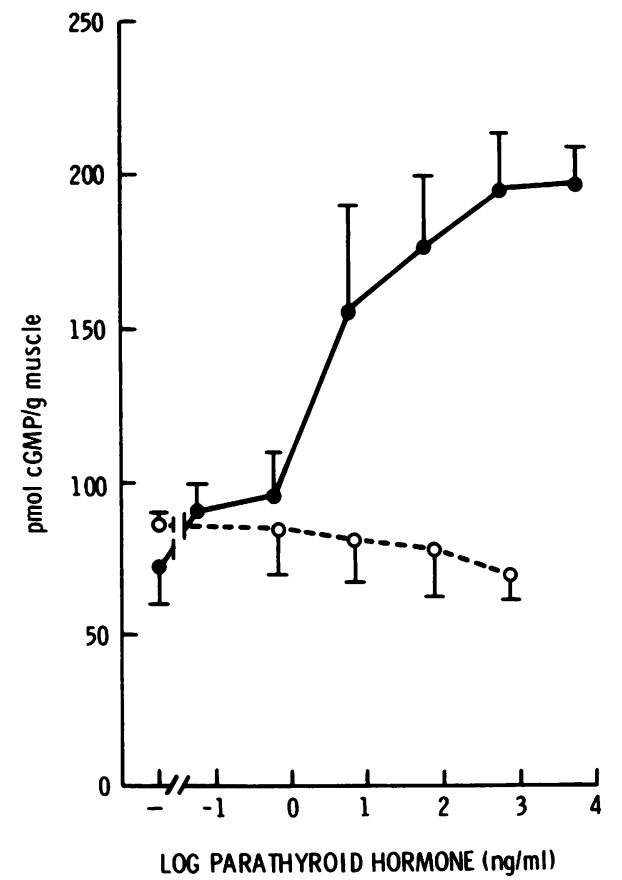

Figure 5 Effect of parathyroid hormone on cGMP levels and skeletal muscle of control and uremic rats. Epitrochlearis preparations from control $(\bullet)$ and chronically uremic $(O)$ rats were obtained and incubated with varying concentrations of parathyroid hormone in Krebs-Henseleit bicarbonate buffer (pH 7.4) containing glucose $(5 \mathrm{mM})$. After the conclusion of the incubation, each muscle was rapidly removed, rinsed, blotted, and frozen in liquid nitrogen. Levels of cGMP in trichloroacetic extracts of each skeletal muscle preparation were then determined by double antibody radioimmunoassay. Values shown are the means ( \pm SEM) for at least 10 experiments and are given as picomoles of cGMP per gram muscle, wet weight. the effects of parathyroid hormone and 3-isobutyl-1methylxanthine on cyclic nucleotide phosphodiesterase activity in vitro were assessed (Table IV). Muscle homogenates incubated with 3-isobutyl-1-methylxanthine in vitro clearly had reduced activities of both the AMP and GMP phosphodiesterase when assayed in subcellular fractions of homogenates. On the other hand, muscle homogenates incubated in the presence of synthetic 1-34 parathyroid hormone had no alteration in AMP or GMP phosphodiesterase activities in homogenates of control muscles. These findings suggest that the effects of synthetic 1-34 parathyroid hormone on rat skeletal muscle cyclic nucleotide levels may not derive from a primary inhibition of cyclic nucleotide degradation.

The effect of parathyroid hormone on skeletal muscle adenylyl cyclase activity was next assessed (Fig. 6). The synthetic 1-34 fragment of bovine parathyroid hormone produced a concentration-dependent stimulation of adenylyl cyclase activity in membrane preparations from muscles of control rats. Those concentrations of parathyroid hormone that stimulated adenylyl cyclase activity were similar to those concentrations that increased muscle cAMP levels (Fig. 4) and altered muscle amino acid release (Figs. 1 and 2). Aged or oxidized preparations of the synthetic 1-34 fragment of bovine parathyroid hormone did not alter adenylyl cyclase activity in this assay system. Potential effects of parathyroid hormone on muscle guanylyl cyclase activities were also studied (Table V). Neither supernatant nor particulate activities of guanylyl cyclase were stimulated by parathyroid hormone using muscle from control and uremic animals. Sodium azide stimulation of supernatant

TABLE IV

Effect of Parathyroid Hormone and 3-Isobutyl-1-Methylxanthine on Phosphodiesterase Activity in Rat Skeletal Muscle

\begin{tabular}{|c|c|c|c|c|c|c|c|}
\hline \multirow[b]{3}{*}{ Incubation media } & \multirow[b]{3}{*}{ Concentration } & \multicolumn{6}{|c|}{ Phosphodiesterase activity } \\
\hline & & \multicolumn{3}{|c|}{ cAMP } & \multicolumn{3}{|c|}{ cGMP } \\
\hline & & Homogenate & $\begin{array}{c}600-g \\
\text { supernatant }\end{array}$ & $\begin{array}{l}40,000-g \\
\text { supernatant }\end{array}$ & Homogenate & $\begin{array}{c}600-g \\
\text { supernatant }\end{array}$ & $\begin{array}{l}\text { 40,000-g } \\
\text { supernatant }\end{array}$ \\
\hline & & \multicolumn{3}{|c|}{ pmol cAMP hydrolyzed/mg protein $/ \mathrm{h}$} & \multicolumn{3}{|c|}{ pmol cGMP hydrolyzed/mg protein $/ \mathrm{h}$} \\
\hline Control & - & $378.6 \pm 8.8$ & $577.8 \pm 21.7$ & $661.9 \pm 26.6$ & $158.3 \pm 14.3$ & $285.5 \pm 12.8$ & $378.4 \pm 18.6$ \\
\hline Parathyroid hormone & $588 \mathrm{ng} / \mathrm{ml}$ & $407.7 \pm 25.6$ & $617.7 \pm 19.6$ & $709.1 \pm 16.1$ & $171.4 \pm 12.1$ & $327.4 \pm 13.6$ & $390.8 \pm 24.9$ \\
\hline $\begin{array}{l}\text { 3-Isobutyl-1- } \\
\text { methylxanthine }\end{array}$ & $0.2 \mathrm{mM}$ & $91.1 \pm 0.4$ & $115.2 \pm 14.3$ & $181.0 \pm 15.3$ & $15.1 \pm 3.6$ & $33.1 \pm 6.3$ & $38.8 \pm 4.4$ \\
\hline
\end{tabular}

Epitrochlaris preparations from control animals were obtained and incubated in Krebs-Henseleit bicarbonate buffer (pH 7.4) containing glucose $(5 \mathrm{mM})$ and parathyroid hormone or methylisobutyl xanthine as indicated. Following a 1-h incubation, muscles were rapidly removed, rinsed, blotted and homogenized and subjected to differential centrifugation. cAMP and cGMP phosphodiesterase activities were assessed in the whole homogenates, the $600-\mathrm{g}$ supernatants and the 40,000-g supernatants of each muscle preparation as described in Methods. Values shown are the means $( \pm \mathrm{SEM})$ for at least five separate experiments and are expressed as picomoles of cyclic nucleotide hydrolyzed per milligram protein/hour. 


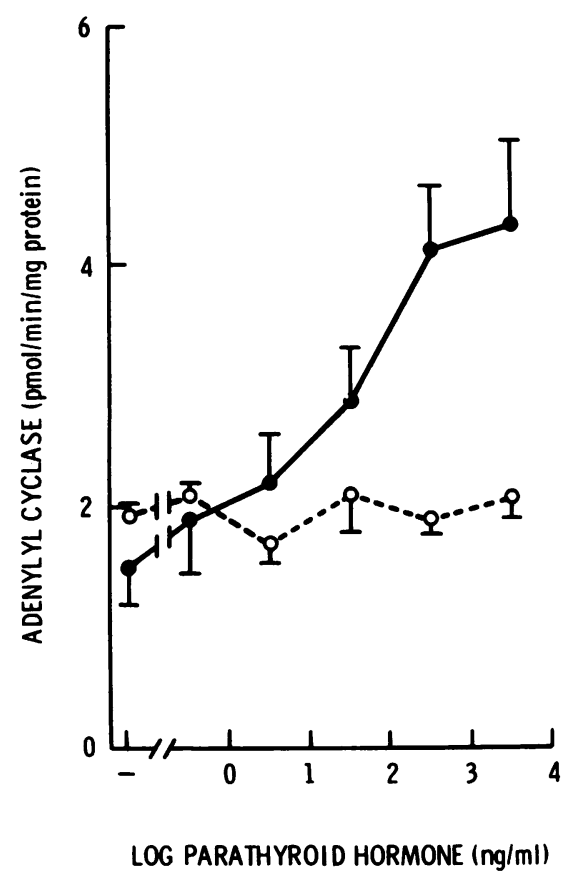

Figure 6 Effect of parathyroid hormone on adenylyl cyclase activity from rat sarcolemma. Skeletal muscle from control $(\odot)$ and chronically uremic $(O)$ rats was obtained and crude sarcolemmal preparations prepared. Adenylyl cyclase activity in the presence of varying concentrations of parathyroid hormone added as indicated was determined radiometrically as the appearance of $\left[{ }^{32} \mathrm{P}\right] \mathrm{cAMP}$ using $\left[\alpha^{-32} \mathrm{P}\right] \mathrm{ATP}$ as substrate. Values shown are the means $( \pm$ SEM) for at least five experiments and are given as picomoles of cAMP formed per minute per milligram protein. guanylyl cyclase activity was reduced in muscle from uremic animals. Furthermore, both supernatant and particulate basal guanylyl cyclase activities were reduced $40-50 \%$ in uremic as compared to control muscle.

In previous studies with muscle of uremic animals we found a diminished responsiveness toward epinephrine and serotonin inhibition of amino acid release. This derived from a desensitization of the epinephrine- and serotonin-stimulable adenylyl cyclase activities in muscle of uremic rats (20). As a consequence, there were diminished increases by these hormones in muscle AMP levels as a function of the epinephrine or serotonin concentration added. In view of the effects of parathyroid hormone on cyclic nucleotide metabolism in skeletal muscle, potential interactions between epinephrine, serotonin, and parathyroid hormone on amino acid release from skeletal muscle were next examined. As shown in Table VI, epinephrine $\left(10^{-5} \mathrm{M}\right)$ decreased alanine and glutamine release from muscle by 36 and $49 \%$, respectively, $(P<0.01)$. Similarly, serotonin $\left(10^{-5} \mathrm{M}\right)$ decreased alanine and glutamine release by 31 and $39 \%$, respectively $(P<$ $0.01)$. Parathyroid hormone alone increased alanine and glutamine release as noted earlier. In the presence of parathyroid hormone, neither epinephrine nor serotonin produced significant inhibition of either alanine or glutamine release from muscle. This result was not the consequence of the single epinephrine or serotonin concentration reported. As shown in Fig. 7, epinephrine produced a concentration-dependent decrease in alanine release from muscles of control an-

TABLE V

Effect of Parathyroid Hormone and Sodium Azide on Guanylyl Cyclase Activity in Skeletal Muscle of Control and Uremic Rats

\begin{tabular}{|c|c|c|c|c|c|}
\hline \multirow[b]{3}{*}{ Additions } & \multirow[b]{3}{*}{ Concentration } & \multicolumn{4}{|c|}{ Guanylyl cyclase activity } \\
\hline & & \multicolumn{2}{|c|}{ Supernatant } & \multicolumn{2}{|c|}{ Particulate } \\
\hline & & Control & Uremic & Control & Uremic \\
\hline & $n g / m l$ & \multicolumn{4}{|c|}{$\mathrm{pmol} / \mathrm{min} / \mathrm{mg}$ protein } \\
\hline Control & - & $20.1 \pm 0.47$ & $12.1 \pm 0.47$ & $8.28 \pm 0.10$ & $3.98 \pm 0.21$ \\
\hline \multirow{5}{*}{ Parathyroid hormone } & 0.59 & $20.8 \pm 0.71$ & $12.1 \pm 0.38$ & $8.29 \pm 0.65$ & $3.16 \pm 0.27$ \\
\hline & 5.88 & $20.1 \pm 0.62$ & $11.7 \pm 0.32$ & $8.29 \pm 0.13$ & $4.14 \pm 0.36$ \\
\hline & 58.8 & $21.1 \pm 0.71$ & $11.2 \pm 0.41$ & $8.06 \pm 0.55$ & $3.25 \pm 0.23$ \\
\hline & 588 & $21.4 \pm 0.79$ & $10.3 \pm 0.35$ & $7.16 \pm 0.65$ & $2.93 \pm 0.45$ \\
\hline & 5,880 & $19.9 \pm 0.88$ & $10.7 \pm 0.45$ & $7.16 \pm 0.71$ & $3.40 \pm 0.12$ \\
\hline Sodium azide, $5 \mathrm{mM}$ & - & $27.9 \pm 0.27$ & $13.3 \pm 0.45$ & $11.9 \pm 1.07$ & $6.32 \pm 0.80$ \\
\hline
\end{tabular}

Epitrochlearis preparations of control and chronically uremic rats were obtained, homogenized, and separated into a 40,000- $g$ supernatant and 40,000- $g$ pellet fractions. Guanylyl cyclase activity was assayed as outlined in Methods using $\left[\alpha-{ }^{32} \mathrm{P}\right]$ GTP as substrate. Values shown for guanylyl cyclase activity are the means $( \pm$ SEM) for at least 12 experiments and are expressed as picomoles/minute/milligram protein. 
TABLE VI

Effect of Synthetic Parathyroid Hormone on the Action of Epinephrine and Serotonin on Amino Acid Release in Rat Skeletal Muscle

\begin{tabular}{|c|c|c|c|}
\hline Addition & Concentration & Alanine release & $\begin{array}{l}\text { Glutamine } \\
\text { release }\end{array}$ \\
\hline & & \multicolumn{2}{|c|}{$\mathrm{nmol} / \mathrm{min} / \mathrm{g}$ muscle } \\
\hline Control & - & $19.97 \pm 1.69$ & $29.54 \pm 3.49$ \\
\hline Parathyroid hormone & $1,000 \mathrm{ng} / \mathrm{ml}$ & $27.53 \pm 0.76$ & $38.80 \pm 2.81$ \\
\hline Epinephrine & $10^{-5} \mathrm{M}$ & $12.87 \pm 0.53$ & $15.21 \pm 2.04$ \\
\hline Serotonin & $10^{-5} \mathrm{M}$ & $13.79 \pm 2.13$ & $17.93 \pm 1.46$ \\
\hline $\begin{array}{l}\text { Parathyroid hormone } \\
\text { + epinephrine }\end{array}$ & $\begin{array}{l}1,000 \mathrm{ng} / \mathrm{ml} \\
10^{-5} \mathrm{M}\end{array}$ & $20.42 \pm 2.45$ & $27.91 \pm 3.74$ \\
\hline $\begin{array}{l}\text { Parathyroid hormone } \\
\text { + serotonin }\end{array}$ & $\begin{array}{l}1,000 \mathrm{ng} / \mathrm{ml} \\
10^{-5} \mathrm{M}\end{array}$ & $21.26 \pm 2.52$ & $25.56 \pm 3.74$ \\
\hline
\end{tabular}

Epitrochlearis preparations from control rats were obtained and incubated for $1 \mathrm{~h}$ at $37^{\circ} \mathrm{C}$ in Krebs-Henseleit bicarbonate buffer (pH 7.4) containing glucose $(5 \mathrm{mM})$ and epinephrine $\left(10^{-5} \mathrm{M}\right)$, serotonin $\left(10^{-5} \mathrm{M}\right)$ and parathyroid hormone as indicated below. At the conclusion of the $1-\mathrm{h}$ incubation, muscles were rapidly removed from the media, rinsed, blotted, and frozen in liquid nitrogen. Alanine and glutamine released to the incubation media were subsequently determined using microfluorometric enzymatic techniques. Values shown are the means $( \pm \mathrm{SEM})$ for at least six experiments and are expressed as nanomoles of amino acid released per minute/gram muscle, wet weight.

imals. In contrast, basal alanine release in the presence of parathyroid hormone was increased and the inhibition by epinephrine was markedly reduced. Indeed, no inhibitory effect of epinephrine on alanine release in the presence of parathyroid hormone was observed with epinephrine concentrations $<10^{-6} \mathrm{M}$. This is in contrast to the effects of epinephrine in the absence of parathyroid hormone in which concentrations of epinephrine as low as $10^{-9} \mathrm{M}$ produced detectable inhibition of alanine release from muscle. A similar loss of responsiveness to epinephrine action was observed in studies of glutamine release (Fig. 8). In absence of added parathyroid hormone, concentrations of epinephrine as low as $10^{-9} \mathrm{M}$ produced detectable inhibition of glutamine release from muscle. However, in the presence of added synthetic 1-34 bovine parathyroid hormone, epinephrine levels of $10^{-6} \mathrm{M}$ or greater were required to produce observable inhibition of glutamine release.

Since the mechanism of epinephrine inhibition of amino acid release from skeletal muscle is linked through alterations in cAMP levels in skeletal muscle, levels of this cyclic nucleotide in these same muscle preparations were examined. As shown in Fig. 9 basal cAMP levels were $\sim 100 \%$ higher in those preparations incubated in the presence of parathyroid hormone as compared with preparations incubated in the absence of parathyroid hormone. In the absence of added parathyroid hormone, epinephrine produced a concentration-dependent increase in cAMP levels similar to that described (20). At $10^{-5} \mathrm{M}$ epinephrine, cAMP levels were increased by $1,670 \mathrm{pmol} / \mathrm{g}$ muscle over levels in the absence of epinephrine. In contrast, increasing concentrations of epinephrine in the presence of parathyroid hormone did not further increase cAMP levels at epinephrine concentrations $<10^{-5} \mathrm{M}$. At $10^{-5} \mathrm{M}$ epinephrine, cAMP levels were increased only 620 $\mathrm{pmol} / \mathrm{g}$ muscle compared with cAMP levels measured in the absence of added epinephrine. Furthermore, cAMP levels in the presence of $10^{-5} \mathrm{M}$ epinephrine plus parathyroid hormone were somewhat less than those levels produced by epinephrine $\left(10^{-5} \mathrm{M}\right)$ in the absence of added parathyroid hormone. Levels of cGMP were also determined (Fig. 10). Epinephrine did not alter cGMP levels in control muscles, nor did it reduce the elevated cGMP levels resulting from 134 parathyroid hormone addition.

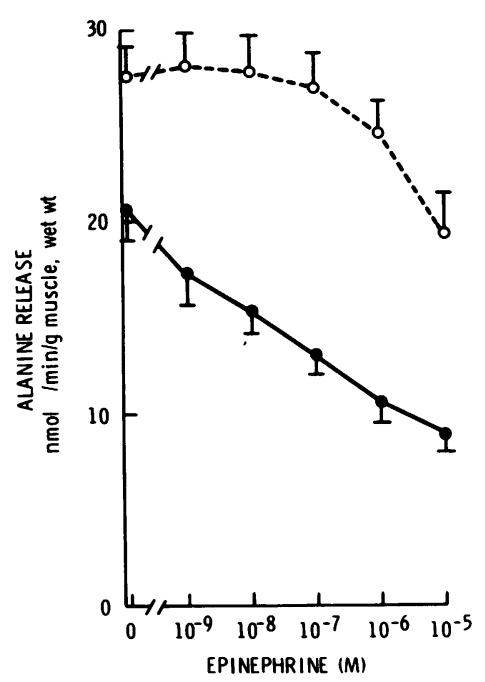

Figure 7 Effect of parathyroid hormone on the epinephrine-induced inhibition of alanine release from skeletal muscle. Epitrochlearis preparations were obtained from normal rats and were incubated for $1 \mathrm{~h}$ at $37^{\circ} \mathrm{C}$ under $95 \% \mathrm{O}_{2}-5 \%$ $\mathrm{CO}_{2}$ in Krebs-Henseleit bicarbonate buffer ( $\mathrm{pH}$ 7.4) containing varying concentrations of epinephrine as indicated either in the presence $(O)$ or the absence $(O)$ of added bovine 1-34 parathyroid hormone $(1,000 \mathrm{ng} / \mathrm{ml})$. At the conclusion of the 1 -h incubation, muscles were removed and rapidly rinsed, blotted, and frozen in liquid nitrogen. Alanine released to the media was determined enzymatically using microfluorometric techniques. Values shown are the means $( \pm \mathrm{SEM})$ for at least six experiments and are expressed as nanomoles of alanine released per minute per gram muscle, wet weight. 


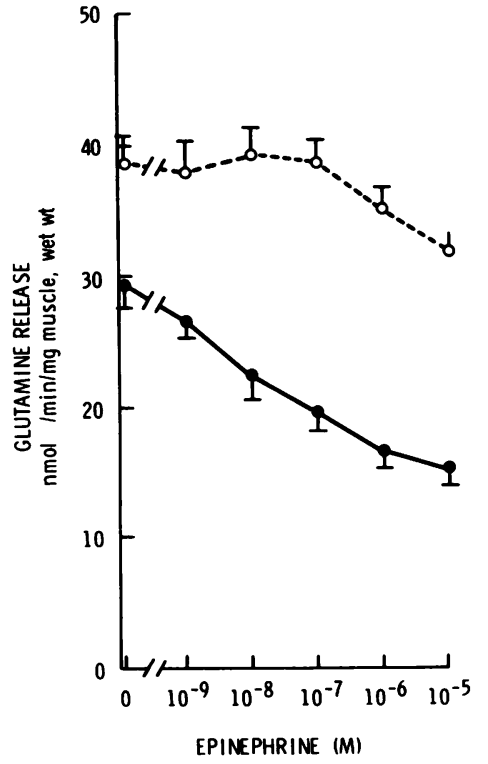

Figure 8 Effect of parathyroid hormone on the epinephrine-induced inhibition of glutamine release from skeletal muscle. Epitrochlearis preparations were obtained from normal rats and were incubated for $1 \mathrm{~h}$ at $37^{\circ} \mathrm{C}$ under $95 \% \mathrm{O}_{2}-$ $5 \% \mathrm{CO}_{2}$ in Krebs-Henseleit bicarbonate buffer ( $\mathrm{pH} 7.4$ ) containing varying concentrations of epinephrine as indicated either in the presence $(O)$ or the absence $(O)$ of added 1-34 bovine parathyroid hormone $(1,000 \mathrm{ng} / \mathrm{ml})$. At the conclusion of the 1-h incubation, muscles were removed and rapidly rinsed, blotted, and frozen in liquid nitrogen. Glutamine released to the media was determined enzymatically using microfluorometric techniques. Values shown are the means $( \pm \mathrm{SEM})$ for at least six experiments and are expressed as nanomoles of glutamine released per minute per gram muscle, wet weight.

The effects of parathyroid hormone on the catecholamine stimulable adenylyl cyclase were next investigated. Rat sarcolemmal preparations were preincubated under adenylyl cyclase assay conditions without added $\left[\alpha-{ }^{32} \mathrm{P}\right] \mathrm{ATP}$ but in the presence or absence of 1-34 parathyroid hormone. Following a 10-min preincubation, membranes were transferred to adenylyl cyclase assay media containing increasing concentrations of isoproterenol (Fig. 11). Membranes preincubated with parathyroid hormone showed a maximal activity of the isoproterenol-stimulable adenylyl cyclase, which was decreased $25 \%$ compared to membranes preincubated in the absence of the 134 polypeptide. This decrease was dependent upon the concentration of parathyroid hormone added to the preincubation media. Preincubation with isoproterenol $\left(10^{-7} \mathrm{M}\right)$ had no effect on the subsequent stimulation of adenylyl cyclase activity by isoproterenol (data not shown).

\section{DISCUSSION}

The results of the present study show clearly that bovine parathyroid hormone as well as the synthetic 134 fragment of bovine parathyroid hormone increase the release of alanine and glutamine from rat skeletal muscle. This increased amino acid release does not derive from a primary alteration in rates of amino acid transport or a nonspecific toxic effect of parathyroid hormone on the skeletal muscle membrane since tissue levels of both alanine and glutamine were unchanged at any parathyroid hormone concentration studied (Table II). Instead, this increased release of alanine and glutamine reflects an increased net synthesis of these two amino acids in skeletal muscle. This conclusion is based on the observation that parathyroid hormone does not alter alanine reutilization via oxidation to $\left[{ }^{14} \mathrm{C}\right] \mathrm{CO}_{2}$ or its incorporation into protein via protein synthesis. Furthermore, in other studies, we have shown that reutilization of alanine and glutamine by skeletal muscle preparations under these conditions of incubation is quantitatively insignificant compared to

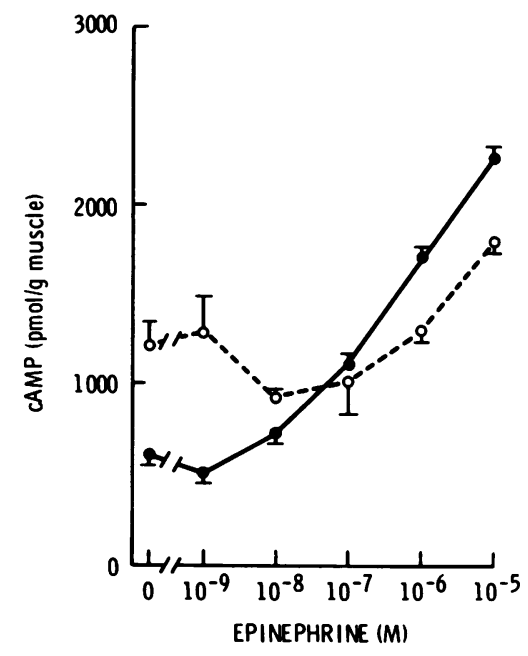

Figure 9 Effect of parathyroid hormone on the epinephrine stimulation of cAMP levels in skeletal muscle. Epitrochlearis preparations of rat skeletal muscle were obtained and incubated in Krebs-Henseleit bicarbonate buffer ( $\mathrm{pH}$ 7.4) containing glucose $(5 \mathrm{mM})$, varying concentrations of epinephrine as indicated either in the presence $(O)$ or in the absence (๑) of added 1-34 bovine parathyroid hormone (1,000 ng/ $\mathrm{ml})$. At the conclusion of the incubation, muscles were rapidly removed, rinsed, blotted, and frozen in liquid nitrogen. Levels of cAMP in each skeletal muscle preparation were determined by double antibody radioimmunoassay in the trichloroacetic extracts of each skeletal muscle preparation. Values shown are the means $( \pm$ SEM) for at least five experiments and are expressed as picomoles of cAMP/gram muscle, wet weight. 


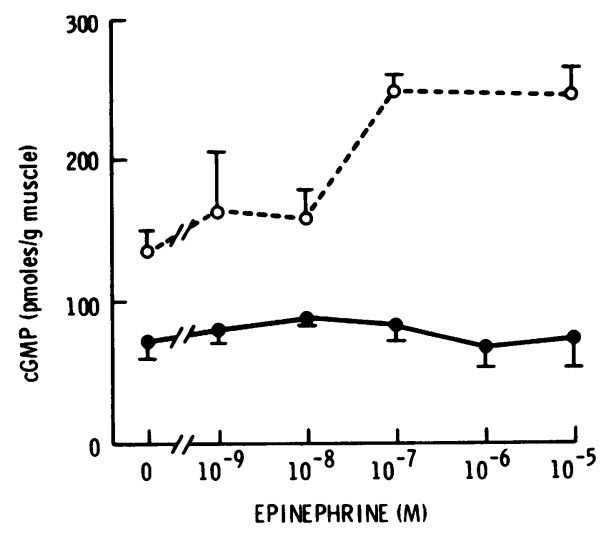

Figure 10 Effect of parathyroid hormone on the epinephrine stimulation of cGMP levels in skeletal muscle. Epitrochlearis preparations of rat skeletal muscle were obtained and incubated for $5 \mathrm{~min}$ at $37^{\circ} \mathrm{C}$ in Krebs-Henseleit bicarbonate buffer ( $\mathrm{pH} 7.4)$ containing glucose $(5 \mathrm{mM})$, varying concentrations of epinephrine as indicated in the presence $(O)$ and the absence of $(\theta)$ of added 1-34 bovine parathyroid hormone $(1,000 \mathrm{ng} / \mathrm{ml})$. At the conclusion of the incubation, muscles were rapidly removed, rinsed, blotted, and frozen in liquid nitrogen. Levels of cGMP in each skeletal muscle preparation were determined by double antibody radioimmunoassay in the trichloroacetic extracts of each skeletal muscle preparation. Values shown are the means ( \pm SEM) for at least five experiments and are expressed as picomoles of cGMP per gram muscle, wet weight.

the amounts of these amino acids released $(21,22)$. Thus, a primary inhibition of alanine reutilization could not account for the data shown in Table I and Figs. 1 and 2. Instead, it seems more reasonable to conclude that parathyroid hormone and the synthetic 1-34 fragment increase directly the formation of alanine and glutamine in skeletal muscle.

Skeletal muscle releases alanine and glutamine to an extent far greater than the release of all other amino acids combined (23-25). In part this preferential release reflects a unique net formation of alanine and glutamine in skeletal muscle. The amino groups required for alanine and glutamine synthesis in muscle are supplied by the catabolism of other amino acids (26-28). Similarly, the carbon requirement for ongoing glutamine and alanine synthesis appears to be met, in part, by the metabolism of other amino acids to form the carbon as well as nitrogen precursors required for continuing alanine and glutamine synthesis in muscle (29). The degradation of endogenous skeletal muscle proteins is the primary process maintaining the ongoing availability of these precursor amino acids (30). Although the increased muscle alanine formation in diabetes mellitus has been attributed to diminished reutilization of amino acids for protein synthesis (31), this may not be the primary mechanism accounting for the increased alanine and glutamine formation produced by parathyroid hormone since the increased amino acid formation (Figs. 1 and 2) was observed at parathyroid hormone concentrations that are four to five orders of magnitude lower than those required for inhibition of protein synthesis (Fig. 3). On the other hand, experiments using labeled amino acid incorporation to assess protein synthesis were necessarily performed in the presence of insulin, whereas experiments on amino acid release were performed in the absence of insulin. It is possible that exogenous insulin may overcome inhibitory effects on protein synthesis of

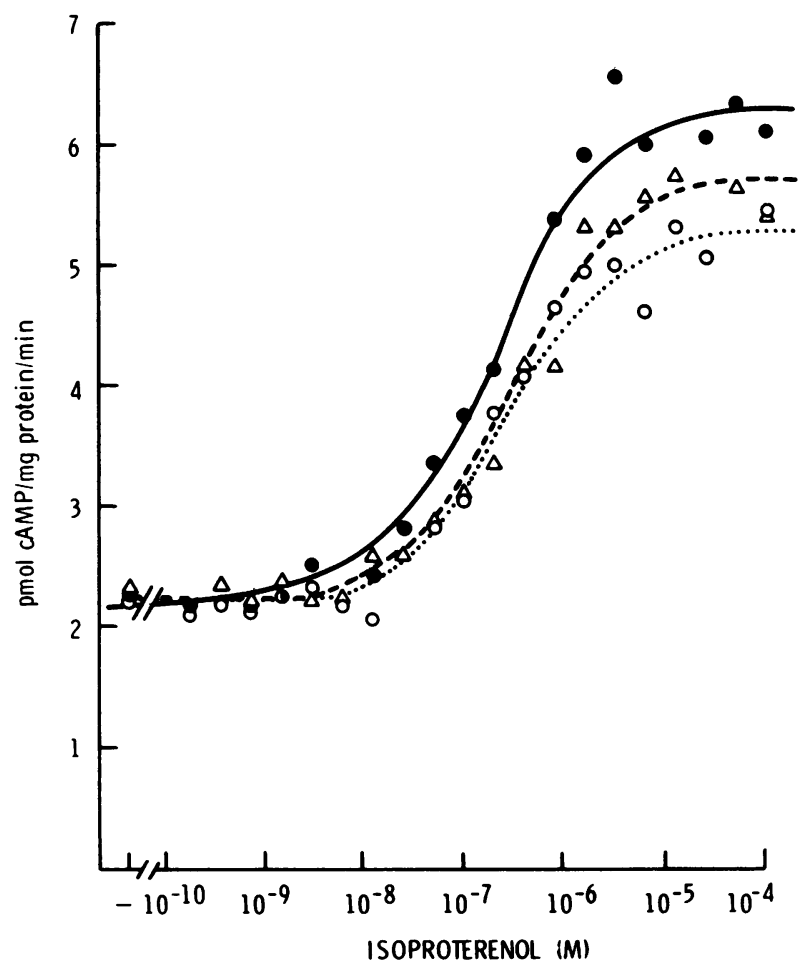

Figure 11 Effect of preincubation with parathyroid hormone on isoproterenol stimulable adenylyl cyclase activity in rat sarcolemma. Skeletal muscle preparations were obtained from control rats and crude preparations of sarcolemma prepared by differential centrifugation. These sarcolemmal preparations were incubated for $10 \mathrm{~min}$ in adenylyl cyclase assay media omitting $\left[\alpha^{-32} \mathrm{P}\right]$ ATP but containing either no added 1-34 bovine parathyroid hormone $(\bullet), 1,000$ $\mathrm{ng} / \mathrm{ml}$ parathyroid hormone $(\Delta)$, or $10,000 \mathrm{ng} / \mathrm{ml}$ of $1-34$ parathyroid hormone $(O)$. After conclusion of the preincubation period, the sarcolemma was used in an adenylyl cyclase activity assay containing varying concentrations of isoproterenol as indicated. Values for adenylyl cyclase activity are the means $( \pm S E M)$ for at least three experiments and are expressed as picomoles of cAMP formed per minute per milligram protein. 
parathyroid hormone at lower concentrations. However, prior studies with insulin alone have shown only a slight effect of insulin even at high concentrations on amino acid release during the $1-h$ incubation period used (23). Furthermore, protein synthesis in muscle from control and uremic animals was inhibited equally, although no effect of parathyroid hormone could be observed on the synthesis and release of alanine and glutamine from uremic muscle. Thus, it seems more reasonable to conclude that a diminished reutilization of amino acids via protein synthesis may not account primarily for the increased rates of alanine and glutamine synthesis produced by parathyroid hormone in this study. Instead, it seems possible that a direct effect of parathyroid hormone on muscle protein degradation may produce the augmentation of alanine and glutamine synthesis and release. Support for this concept is provided by the data in Table III in which muscles from rats given a pulse-chase administration of [guanido $-{ }^{14} \mathrm{C}$ ]arginine in vivo were subsequently incubated in vitro with and without exogenous parathyroid hormone. Although this experiment provides primarily a qualitative assessment of net muscle proteolysis in vitro and potential effects on protein resynthesis cannot be entirely excluded, the data suggest that parathyroid hormone may increase substantially the degradation of endogenously labeled muscle proteins. Since the initial rate of net protein degradation in these studies using labeled arginine $(3.06 \% / \mathrm{h})$ agrees well with initial rates determined by Fulks et al. (32) using labeled phenylalanine release $(2.87 \% / \mathrm{h})$, and since parallel studies performed with cycloheximide yielded similar results as noted previously (33), it seems reasonable to conclude that parathyroid hormone may act on skeletal muscle primarily by increasing muscle proteolysis, thereby increasing the availability of amino acid precursors, which in turn causes an acceleration in the synthesis and release of alanine and glutamine.

The precise mechanisms by which parathyroid hormone alters protein and amino acid metabolism in skeletal muscle are not entirely clear. In previous studies, we have shown that cyclic nucleotide associated agonists regulate muscle protein degradation and alanine and glutamine synthesis and release. For example, $\beta_{2}$-adrenergic agonists, acting through a specific hormone stimulable adenylyl cyclase and increased intracellular levels of cyclic AMP retard muscle protein degradation and thereby inhibit alanine and glutamine synthesis and release $(34,35)$. Similarly, serotonin acting through a specific sarcolemmal D-serotonergic receptor and a hormone stimulable adenylyl cyclase also increases muscle cAMP levels and thereby inhibits protein degradation and alanine and glutamine syn- thesis and release $(21,35)$. On the other hand, cholinergic agonists acting through a nicotinic cholinergic receptor increase muscle cGMP levels and as a result increase muscle protein degradation and the formation and release of alanine and glutamine $(22,36)$. The results of the present study show clearly that those concentrations of parathyroid hormone that affect protein and amino acid metabolism also increase cAMP and cGMP levels in muscle. Studies of parathyroid hormone action have described specific hormone stimulable adenylyl cyclases for parathyroid hormone in kidney as well as in bone calvaria cells (37-39). A similar parathyroid hormone-stimulable adenylyl cyclase also appears to be present in skeletal muscle (Fig. 6). Concentrations of parathyroid hormone that alter protein and amino acid metabolism in skeletal muscle and increase cyclic AMP levels also stimulate muscle adenylyl cyclase activity in crude sarcolemmal preparations.

If the metabolic effects of parathyroid hormone on skeletal muscle protein and amino acid metabolism were mediated solely by the increased cAMP levels, then one would expect inhibition of protein degradation and amino acid release in these muscle preparations, analogous to the metabolic actions of adrenergic and serotonergic agonists. To the contrary, parathyroid hormone produced an opposite metabolic effect, increasing rather than decreasing muscle proteolysis and amino acid release. Such an effect is entirely consistent with the elevated cGMP levels produced by parathyroid hormone addition in these in vitro muscle incubation systems, and is analogous to the effect of nicotinic cholinergic agonists that also increase muscle cGMP levels and accelerate proteolysis and amino acid release (36). Parathyroid hormone action is not classically associated with increased cGMP levels in other tissues and no measurable stimulation of skeletal muscle guanylyl cyclase by parathyroid hormone could be demonstrated. However, traditional mechanisms of hormone receptor-adenylyl cyclase coupling do not appear to apply to the regulation of guanylyl cyclase since specific receptor-mediated stimulations of guanylyl cyclase have not been described, and since this cyclase may be regulated primarily by other factors such as the oxidation-reduction potential (40), or by calcium flux (41). Taken as a whole, the data of the present study suggest that the accelerated protein degradation and amino acid release produced by parathyroid hormone in skeletal muscle may be the result of an increased cGMP level rather than the effect of the increased cAMP level produced by parathyroid hormone. Nevertheless, the precise mechanism by which parathyroid hormone might increase cGMP levels remains unclear. 
In this study, parathyroid hormone concentrations of $1-10 \mathrm{ng} / \mathrm{ml}$ were found to cause significant alterations of skeletal muscle protein, amino acid, and cyclic nucleotide metabolism (Figs. 1, 2, 4 and 5) in vitro and $30-300 \mathrm{ng} / \mathrm{ml}$ significantly stimulated muscle adenylyl cyclase activity (Fig. 6). These levels compare favorably with concentrations of parathyroid hormone used in other studies on bone and kidney adenylyl cyclase activation that used levels of 10,000 and $85,000 \mathrm{ng} / \mathrm{ml}$, respectively $(39,37)$, and with other in vitro studies of parathyroid hormone action on kidney and bone metabolism $(42,43)$. The quantities of parathyroid hormone producing significant metabolic effects in this study in vitro are approximately one to two orders of magnitude greater than circulating levels of parathyroid hormone in normal man $(0.50 \mathrm{ng} / \mathrm{ml}$; $44,45)$. Parathyroid hormone levels may be 30 - to 100 fold greater in primary hyperparathyroidism and in chronic uremia, respectively (44-47). Thus, effective concentrations of parathyroid hormone in this study in vitro are not greatly dissimilar from concentrations of hormone observed in vivo (44-47). In other systems, supraphysiologic levels of hormones have also been used for demonstrations of hormonal actions in vitro. For example, in studies on insulin regulation of glucose and protein metabolism in skeletal muscle in vitro insulin concentrations of 1,000 to $25,000 \mu \mathrm{U} / \mathrm{ml}$, which are 20 - to 500 -fold greater than insulin levels noted in vivo have been used $(31,48)$. Studies of glucagon stimulation of liver and heart adenylyl cyclase activity and of hepatic glucose production and lipolysis in vitro have used glucagon concentrations that are 350 - to 10,000 -fold greater than circulating glucagon concentrations in vivo (49-52). The precise mechanisms that might account for the discrepancies between levels of hormone required for in vitro demonstrations of hormone action as compared with levels of these same hormones found in vivo are unknown.

In contrast to the metabolic effects of parathyroid hormone on muscle obtained from control animals, no action of either intact 1-84 bovine parathyroid hormone or the synthetic 1-34 fragment of bovine parathyroid hormone on muscle amino acid release, cAMP and cGMP levels, or on adenylyl cyclase activity could be observed in skeletal muscle from uremic animals. Although these findings may be interpreted as being consistent with prior saturation of parathyroid hormone receptors in muscle by the high levels of circulating parathyroid hormone in chronic uremia (46, 47), alternative interpretations are also possible such as a complete desensitization or loss of hormone responsiveness or potentially altered cation pools and channels owing to the hypocalcemia and hyperphosphatemia also associated with chronic uremia $(53,54)$.
In previous studies we observed a desensitization of muscles from uremic animals to epinephrine and serotonin action on skeletal muscle amino acid and cyclic nucleotide metabolism $(10,20)$. The mechanism for such a desensitization or diminution of hormone responsiveness was not apparent at that time. However, it is particularly noteworthy that incubation of muscles with either epinephrine or serotonin in the presence of added parathyroid hormone reproduced in vitro this same desensitization and diminished responsiveness with respect to amino acid release in muscle of normal animals compared with the previously observed desensitization in muscles obtained from uremic animals (10). Thus a 1,000 to 10,000 -fold excess of epinephrine was required to produce an equal decrease in alanine and glutamine release in the presence of added parathyroid hormone as compared with incubations in the absence of parathyroid hormone (Figs. 7 and 8). This same degree of altered responsiveness was previously reported in muscles from uremic animals (10).

In the present study, basal cAMP levels in the presence of added parathyroid hormone (Fig. 9) were $\sim 100 \%$ higher in normal preparations than cAMP levels in the absence of added parathyroid hormone. Despite this, amino acid release was greater in those preparations incubated in the presence of parathyroid hormone, suggesting the presence of an additional factor producing resistance to cAMP action such as perhaps the increase in cGMP levels observed in the presence of parathyroid hormone. This resistance to cAMP action was also noted previously in uremic muscle. However, cAMP resistance alone cannot be the sole explanation for the diminished responsiveness to epinephrine observed in the presence of parathyroid hormone since the increment above basal cAMP levels produced by increasing concentrations of epinephrine was less in muscle incubated with parathyroid hormone than in muscle incubated in the absence of parathyroid hormone. This suggests that an acquired impairment to catecholamine-stimulated cAMP formation was also produced by simultaneous co-incubation with parathyroid hormone. As a consequence of this impairment in cAMP generation, there was also a diminished responsiveness of amino acid release to epinephrine and serotonin. The basis for these effects of parathyroid hormone is not entirely clear. It is possible that added parathyroid hormone produces a heterologous desensitization of muscle adenylyl cyclase, which would account for the diminished increments in cAMP levels produced by incubation with parathyroid hormone and either epinephrine or serotonin. Evidence for such a desensitization is presented in Fig. 11 in which preincubation with parathyroid hormone rendered rat sarcolemma less sensitive to isoproterenol. Although the 
concentration of isoproterenol producing one-half maximal stimulation of adenylyl cyclase was not changed by preincubation with parathyroid hormone, the maximal cyclase activity was reduced in amounts proportional to the concentration of parathyroid hormone in the preincubation media. No such effect for isoproterenol, epinephrine, or serotonin preincubation or co-incubation were noted (data not shown). These findings are quite similar to heterologous desensitizations observed in other systems $(55,56)$. It is also possible that the increased cGMP levels produced by parathyroid addition may have modified the formation of cAMP by epinephrine or serotonin. Precedence for such a mechanism is suggested by studies with cardiac muscle in which muscarinic cholinergic stimulation was found to produce a reduced adrenergic receptor affinity and reduced hormone stimulable adenylyl cyclase activity as well as reduced levels of cAMP in those preparations (57-59). Muscarinic cholinergic stimulation is also associated with cGMP elevation in some experiments (59). Irrespective of the precise mechanism, the results of the present study show clearly that incubation of skeletal muscle in vitro with parathyroid hormone can produce a diminished responsiveness to epinephrine and serotonin regulation of protein, amino acid, and cyclic nucleotide metabolism in vitro and that this phenomenon is remarkably similar to the desensitization in muscle obtained from chronically uremic animals towards epinephrine and serotonin modulation of protein, amino acid, and cyclic nucleotide metabolism. Taken as a whole, the data of the present study suggest that high levels of parathyroid hormone may have direct effects on skeletal muscle metabolism and that these effects may account in part for the abnormalities of skeletal muscle noted in chronic uremia and primary hyperparathyroidism.

\section{ACKNOWLEDGMENTS}

We are indebted to Jannie Corbin, Deborah Ehler, Yael Harari, Carol Maillet, and Nurit Shimoni for their excellent technical assistance. The advice and commentary of Drs. James B. Field, Mark L. Entman, and Lutz Birnbaumer are gratefully acknowledged.

This work was supported in part by grants RR 00350 and NS15950 from the National Institutes of Health and grants from the Texas Diabetes Foundation and the Fondren Foundation.

\section{REFERENCES}

1. Horton, E. S., C. Johnson, and H. E. Lebevitz. 1968. Carbohydrate metabolism in uremia. Ann. Intern. Med. 68: $63-74$.

2. Lowrie, E. G., J. S. Soeldner, C. L. Hampers, and J. P. Merrill. 1970. Glucose metabolism and insulin secretion in uremic, pre-diabetic and normal subjects. J. Lab. Clin. Med. 76: 603-615.

3. Perkoff, G. T., C. L. Thomas, J. D. Newton, J. C. Sellman, and F. H. Taylor. 1958. Mechanisms of impaired glucose tolerance in uremia and experimental hyperazotemia. Diabetes. 7: 375-383.

4. Garber, A. J., D. M. Bier, P. E. Cryer, and A. S. Pagliara. 1974. Hypoglycemia in compensated chronic renal insufficiency: substrate limitation of gluconeogenesis. $D i$ abetes. 23: 982-986.

5. Frizzell, M., P. R. Larsen, and J. B. Field. 1973. Spontaneous hypoglycemia associated with chronic renal failure. Diabetes. 22: 493-498.

6. Slatopolsky, E., K. Martin, and K. Hruska. 1980. Parathyroid hormone metabolism and its potential as a uremic toxin. Am. J. Physiol. 239: F1-F12.

7. Patten, B. M., J. P. Bilezikian, L. E. Mallette, A. Prince, W. K. Engel, and G. D. Aurbach. 1974. Neuromuscular disease in primary hyperthyroidism. Ann. Intern. Med. 80: 182-193.

8. Smith, R., and G. Stern. 1967. Myopathy, osteomalacia, and hyperparathyroidism. Brain. 90: 593-602.

9. Choeod, E. G., M. D. Haust, A. J. Hudson, and F. N. Lewis. 1970. Myopathy in primary familial hyperthyroidism. Am. J. Med. 48: 700-707.

10. Garber, A. J. 1978. Skeletal muscle protein and amino acid metabolism in experimental chronic uremia in the rat. Accelerated alanine and glutamine formation and release. J. Clin. Invest. 62: 623-632.

11. Harter, J. R., I. E. Karl, S. Klahr, and D. M. Kipnis. 1979. Effects of reduced renal mass and dietary protein uptake on amino acid release and glucose uptake by rat muscle in vitro. J. Clin. Invest. 64: 513-523.

12. Karl, I. E., A. S. Pagliara, and D. M. Kipnis. 1972. A microfluorometric enzymatic assay for the determination of alanine and pyruvate in plasma and tissue. $J$. Lab. Clin. Med. 80: 434-441.

13. Hohorst, H. J. 1965. In Methods in Enzymatic Analysis. H. V. Bergmeyer, editor. Academic Press, Inc., New York. pp. 266-270.

14. Steiner, A. L., C. W. Parker, and D. M. Kipnis. 1972. Radioimmunoassay for cyclic nucleotides. J. Biol. Chem. 247: 1106-1113.

15. Birnbaumer, L. 1979. In Laboratory Methods Manual for Hormone Action and Molecular Endocrinology. W. T. Schrader and B. W. O'Malley, editors. 3rd edition. The Endocrine Society, Bethesda, MD. 901-919.

16. Bochaert, J. M., M. Hunzicker-Dunn, and L. Birnbaumer. 1976. Hormone-stimulated desensitization of hormone dependent adenylyl cyclase. Dual action of luteinizing hormone of pig graffian follicle. J. Biol. Chem. 251: 2653-2663.

17. Salomon, Y., C. Londos, and M. Rodbell. 1974. A highly sensitive adenylate cyclase assay. Anal. Biochem. 58: 541-548.

18. Lowry, O. H., N. J. Rosebrough, A. L. Farr, and R. J. Randall. 1951. Protein measurement with Folin phenol reagent. J. Biol. Chem. 193: 265-275.

19. Snedecor, G. W., and W. G. Cochran. 1967. Statistical Methods. Iowa State University Press, Ames, Iowa. 6th edition. 380.

20. Garber, A. J. 1978. The regulation of skeletal muscle alanine and glutamine formation and release in experimental chronic uremia in the rat. Subsensitivity of ad- 
enylate cyclase and amino acid release to epinephrine and serotonin. J. Clin. Invest. 62: 633-641.

21. Garber, A. J. 1977. Inhibition by serotonin of amino acid release and protein degradation in skeletal muscle. $\mathrm{Mol}$. Pharmacol. 13: 640-651.

22. Garber, A. J., Y. Harari, and M. L. Entman. 1978. Cholinergic stimulation of alanine and glutamine formation and release from skeletal muscle. J. Biol. Chem. 253: 7918-7923.

23. Garber, A. J., I. E. Karl, and D. M. Kipnis. 1976. Alanine and glutamine synthesis and release from skeletal muscle. I. Glycolysis and amino acid release. J. Biol. Chem. 251: 826-835.

24. Ruderman, N. B., and M. Berger. 1974. The formation of glutamine and alanine in skeletal muscle. J. Biol. Chem. 249: 5500-5506.

25. Pozefsky, T., P. Felig, J. D. Tobin, J. S. Soeldner, and G. F. Cahill, Jr. 1969. Amino acid balance across tissues of the forearm in postabsorptive man. Effects of insulin at two dose levels. J. Clin. Invest. 48: 2273-2283.

26. Garber, A. J., I. E. Karl, and D. M. Kipnis. 1976. Alanine and glutamine synthesis and release from skeletal muscle. II. The precursor role of amino acids in alanine and glutamine synthesis. J. Biol. Chem. 251: 836-843.

27. Snell, K. 1979. Alanine as a gluconeogenic carrier. Trends Biochem. Sci. 4: 124-128.

28. Tischler, M. E., M. Desautels, and A. L. Goldberg. 1982. Does leucine, leucyl-tRNA, or some metabolite of leucine regulate protein synthesis and degradation in skeletal and cardiac muscle? J. Biol. Chem. 257: 1613-1621.

29. Snell, K., and D. A. Duff. 1977. The release of alanine by rat diaphragm muscle in vitro. Biochem. J. 162: 399403.

30. Lee, S. H., and E. J. Davis. 1979. Carboxylation and decarboxylation reactions. Anaplerotic flux and removal of citrate cycle intermediates in skeletal muscle. J. Biol. Chem. 254: 420-430.

31. Jefferson, L. S., D. E. Runnels, B. L. Munger, and H. E. Morgan. 1974. Insulin in the regulation of protein turnover in heart and skeletal muscle. Fed. Proc. 33: 10981104.

32. Fulks, R. M., J. B. Li, and A. L. Goldberg. 1975. Effects of insulin, glucose, and amino acids on protein turnover in rat diaphragm. J. Biol. Chem. 250: 290-298.

33. Garber, A. J., R. J. Schwartz, C. L. Seidel, A. Silvers, and M. L. Entman. 1980. Skeletal muscle protein and amino acid metabolism in hereditary mouse muscular dystrophy. Accelerated protein turnover and increased alanine and glutamine formation and release. J. Biol. Chem. 255: 8315-8324.

34. Garber, A. J., I. E. Karl, and D. M. Kipnis. 1976. Alanine and glutamine synthesis and release in skeletal muscle. IV. $\beta$-Adrenergic inhibition of amino acid release. $J$. Biol. Chem. 251: 851-857.

35. Garber, A. J. 1980 . The impact of streptozotocin-induced diabetes mellitus on cyclic nucleotide regulation of skeletal muscle amino acid metabolism in the rat. $J$. Clin. Invest. 65: 478-487.

36. Garber, A. J., M. L. Entman, and L. Birnbaumer. 1978. Cholinergic stimulation of skeletal muscle alanine and glutamine formation and release. Evidence for mediation by a nicotinic cholinergic receptor and guanosine 3',5'-monophosphate. J. Biol. Chem. 253: 7924-7930.

37. Goltzmann, D., A. Peytremann, E. Callahan, G. W. Tregear, and J. T. Potts, Jr. 1975. Analysis of the require- ments for parathyroid hormone action in renal membranes with the use of inhibiting analogues. J. Biol. Chem. 250: 3199-3203.

38. Marcus, R., and G. D. Aurbach. 1969. Bioassay of parathyroid hormone in vitro with a stable preparation of adenyl cyclase from rat kidney. Endocrinology. 85: 801810.

39. Chase, L. R., S. A. Fedak, and G. D. Aurbach. 1969. Activation of skeletal adenyl cyclase by parathyroid hormone in vitro. Endocrinology. 84: 761-768.

40. Goldberg, N. D., G. Graff, M. K. Haddox, J. H. Stephenson, D. B. Glass, and M. E. Moser. 1977. Oxidative activation of guinea pig splenic cell guanylate cyclase activity by dehydroascorbate, ascorbate, fatty acid hydroperoxides and prostaglandin endoperoxides. Adv. Enzyme Reg. 16: 165-191.

41. Kimura, H., and F. Murad. 1975. Two forms of guanylate cyclase in mammalian tissues and possible mechanisms for their regulation. Metab. Clin. Exp. 24: 439445.

42. Puschett, J. B., and P. Zurbach. 1976. Acute effects of parathyroid hormone on proximal bicarbonate transport in dog. Kidney Int. 9: 501-510.

43. Mahgoub, A., and P. H. Stern. 1974. Carbon dioxide and the effect of parathyroid hormone on bone in vitro. Am. J. Physiol. 266: 1272-1275.

44. G. V. Segre, J. F. Habener, D. Powell, G. W. Tregear, and J. P. Potts, Jr. 1972. Parathyroid hormone in human plasma. Immunochemical characterization and biological implications. J. Clin. Invest. 51: 3163-3172.

45. Deftos, L. J., and J. G. Parthemore. 1974. Secretion of parathyroid hormone in patients with medullary thyroid carcinoma. J. Clin. Invest. 54: 416-420.

46. Jacob, A. J., D. Lanier, J. Canterbury, and J. J. Bourgoigne. 1980. Reduction by cimetidine of serum parathyroid hormone levels in uremic patients. N. Engl. J. Med. 302: 671-674.

47. Reiss, E., and J. Canterbury. 1967. A radioimmunoassay for circulating parathyroid hormone in man: preliminary results. J. Lab. Clin. Med. 70: 1012-1013. (Abstr.)

48. Chaisson, J.-L., M. R. Dietz, H. Shikama, M. Wootten, and J. H. Exton. 1980. Insulin regulation of skeletal muscle glycogen metabolism. Am. J. Physiol. 239: E69E74.

49. Birnbaumer, L., S. L. Pohl, and M. Rodbell. 1971. The glucagon-sensitive adenylyl cyclase system in plasma membranes of rat liver. II. Comparison between glucagon- and fluoride-stimulated activities. J. Biol. Chem. 246: $1857-1860$.

50. Clark, Jr., C. M., B. Beatty, and D. O. Allen. 1973. Evidence for delayed development of the glucagon receptor of adenylate cyclase in the fetal and neonatal rat heart. J. Clin. Invest. 52: 1018-1025.

51. Exton, J. H., and C. R. Park. 1968. Control of gluconeogenesis in liver. II. Effects of glucagon, catecholamines and adenosine $3^{\prime}, 5^{\prime}$-monophosphate on gluconeogenesis in perfused rat liver. J. Biol. Chem. 243: 41814196.

52. Heimberg, M., I. Weinstein, and M. Kohout. 1969. The effects of glucagon, dibutyryl cyclic adenosine $3^{\prime}, 5^{\prime}$ monophosphate and concentration of free fatty acid on hepatic lipid metabolism. J. Biol. Chem. 244: 51315139.

53. Parfitt, A. M. 1976. The actions of parathyroid hormone on bone: relation to bone remodeling and turnover, cal- 
cium homeostasis, and metabolic bone disease. Part IV of IV parts. The state of the bones in uremic hyperparathyroidism - the mechanisms of skeletal resistance to $\mathrm{PTH}$ in renal failure and pseudo-hypoparathyroidism and the role of PTH in osteoporosis, osteopetrosis, and osteofluorosis. Metab. Clin. Exp. 25: 1157-1188.

54. Kaplan, M. A., J. M. Canterbury, G. Gavellas, D. Jaffe, J. J. Bourgoignie, E. Reiss, and N. S. Bricker. 1978. The calcemic and phosphatic effects of parathyroid hormone in the normal and uremic dog. Metab. Clin. Exp. 27: 1785-1792.

55. Lefkowitz, R. J., D. Mullikin, C. L. Wood, T. B. Gore, and C. Mukherjee. 1977. Regulation of prostaglandin receptors by prostaglandins and guanine nucleotides in frog erythrocytes. J. Biol. Chem. 252: 5295-5303.

56. Johnson, G. L., B. B. Wolfe, T. K. Harden, P. B. Holinoff, and J. P. Perkins. 1978. Role of $\beta$-adrenergic receptors in catecholamine-induced desensitization of adenylate cyclase in human astrocytoma cells. J. Biol. Chem. 253: 1472-1480.

57. Lee, T. P., J. F. Kuo, and P. Greengard. 1971. Regulation of myocardial cyclic AMP by isoproterenol, glucagon, and acetylcholine. Biochem. Biophys. Res. Commun. 45: 991-997.

58. Watanabe, A. M., M. M. McConnaughey, R. A. Strawbridge, J. W. Fleming, L. R. Jones, and H. R. Besch, Jr. 1978. Muscarinic cholinergic receptor modulation of $\beta$-adrenergic receptor affinity for catecholamines. $J$. Biol. Chem. 253: 4833-4836.

59. Watanabe, A. M., and H. R. Besch, Jr. 1975. Interaction between cyclic adenosine monophosphate and cyclic guanosine monophosphate in guinea pig ventricular myocardium. Circ. Res. 37: 309-317. 